\title{
Prevalence and risk factors for trachoma in Sarlahi district, Nepal
}

Joanne Katz, Keith P West, Jr, Subarna K Khatry, Steven C LeClerq, Elizabeth Kimbrough Pradhan, M D Thapa, Sharadar Ram Shrestha, Hugh R Taylor

\section{Department of International Health, The Johns Hopkins University, School of Hygiene and Public \\ Health, and the Dana \\ Center for Preventive Ophthalmology, \\ Baltimore, Maryland, \\ USA \\ J Katz \\ K P West, Jr \\ $S$ C LeClerq \\ E K Pradhan}

National Society for the Prevention of

Blindness and the

World Health

Organisation

Prevention of

Blindness Programme,

Kathmandu, Nepal

S K Khatry

M D Thapa

$S$ Ram Shrestha

Department of

Ophthalmology,

University of

Melbourne,

Melbourne, Australia

H R Taylor

Correspondence to: Dr Joanne Katz, Johns Hopkins School of Hygiene and Public Health, Room 5515, 615 N Wolfe Street, Baltimore, MD 21205-2103, USA.

Accepted for publication 28 June 1996

\begin{abstract}
Aims-To estimate the prevalence of trachoma in preschool children in Sarlahi district, Nepal, and to identify risk factors for the disease.

Methods-A stratified random sample of 40 wards was selected for participation in a trachoma survey. Within each ward, a systematic $20 \%$ sample of children 24-76 months of age was chosen to determine the presence and severity of trachoma using the World Health Organisation grading system.
\end{abstract}

Results-A total of 891 children were selected and $836(93.8 \%)$ were examined for trachoma from December 1990 to March 1991. The prevalence of active trachoma was $23.6 \%$ (21.9\% follicular and $1.7 \%$ intense inflammatory). Cicatricial trachoma was not seen in this age group. The prevalence of trachoma ranged from 0 to $50 \%$ across wards with certain communities at much higher risk for trachoma than others. Three year old children had the highest prevalence of follicular $(25.5 \%)$ and intense inflammatory trachoma (4.3\%). Males and females had similar prevalence rates. Wards without any tube wells were at higher risk than those with one or more tube wells. Lower rates of trachoma were seen in families who lived in cement houses, had fewer people per room, more servants, more household goods, animals, and land. Hence, less access to water, crowding and lower socioeconomic status were risk factors for trachoma.

Conclusions-Although follicular trachoma is prevalent, intense inflammatory trachoma is relatively rare and scarring was not observed in this preschool population. Hence, this population may not be at high risk for repeat infections leading to blindness in adulthood.

(Br f Ophthalmol 1996;80:1037-1041)

Trachoma is the second leading cause of blindness worldwide. ${ }^{12}$ It is estimated that 6 million people are currently blind from trachoma and that 500 million are infected. A national blind- ness survey conducted in Nepal in 1981 found that trachoma was the second most common ocular disorder in the country and the second leading cause of blindness in women. ${ }^{34}$ Inflammatory trachoma was more prevalent among certain ethnic groups and in certain areas, particularly in the far west of the country. More recent information on the prevalence of trachoma is not available. Other than a few demographic characteristics described in the Nepal Blindness Survey, risk factors for trachoma in Nepal have not been studied. We conducted a prevalence survey of active trachoma from December 1990 to March 1991 in the east central terai district of Sarlahi in order to assess the magnitude of the current trachoma problem in this area, and to identify risk factors associated with this disease in preschool children.

\section{Materials and methods}

This trachoma survey was conducted within the framework of a larger study assessing the impact of vitamin A supplementation on mortality, morbidity, growth, and xerophthalmia..$^{5-7}$ The sampling plan has been described elsewhere. ${ }^{58}$ Briefly, 29 village development areas were selected at random from a list of village development areas in Sarlahi that were included in the sampling frame on the basis of accessibility and distance from the Indian border. Each village development area is made up of nine administrative areas known as wards. Using a random start, a $15 \%$ systematic sample of 40 wards out of the possible 261 was selected to participate in an ocular survey. A house to house census of preschool children was conducted in September 1989 and updated at 4 monthly intervals. In December 1990 , a systematic $20 \%$ subsample of children in the 40 ocular survey wards who were between 24 and 76 months of age was selected to be examined for signs of trachoma. The survey took 4 months to complete and took place in the season after monsoon (July to September) but before the driest time of year (April to June). The target sample size was calculated to allow for estimation of a $25 \%$ prevalence rate with a $95 \%$ confidence interval from $22 \%$ to $28 \%$. 
Table 1 Prevalence of trachoma by age in Sarlahi, Nepal

\begin{tabular}{|c|c|c|c|c|c|c|c|}
\hline \multirow[b]{2}{*}{ Age (years) } & \multirow[b]{2}{*}{ No } & \multicolumn{2}{|c|}{ Follicular } & \multicolumn{2}{|c|}{ Inflammatory } & \multicolumn{2}{|c|}{ All active trachoma } \\
\hline & & $n$ & $\%$ & $n$ & $\%$ & $n$ & $\%$ \\
\hline 2 & 187 & 46 & 24.6 & 1 & 0.5 & 47 & 25.1 \\
\hline 3 & 141 & 36 & 25.5 & 6 & 4.3 & 42 & 29.8 \\
\hline 4 & 192 & 45 & 23.4 & 2 & 1.0 & 47 & 24.5 \\
\hline 5 & 231 & 38 & 16.5 & 5 & 2.2 & 43 & 18.6 \\
\hline 6 & 85 & 18 & 21.2 & 0 & 0.0 & 18 & 21.2 \\
\hline Total & 836 & 183 & 21.9 & 14 & 1.7 & 197 & 23.6 \\
\hline
\end{tabular}

Trachoma was graded according to the current simplified World Health Organisation grading scheme. ${ }^{910}$ An ophthalmologist and a senior ophthalmic assistant with more than 10 years experience examined the children at one or more central sites in each ward. Both had undergone extensive training in the World Health Organisation grading scheme by an expert against whom they were found to have acceptable agreement before the start of the survey. The examination was done with $2.5 \times$ loupes. The upper lid was everted and the tarsal conjunctiva was examined for signs of trachoma. Active inflammatory disease was classified into follicular trachoma (TF) if five or more follicles were observed on the tarsal plate. Intense inflammatory trachoma (TI) was defined as hypertrophy that obscured more than half of the normal deep tarsal vessels. Cicatricial trachoma was graded as the presence of conjunctival scarring (TS) or trichiasis due to scarring (TT), and corneal opacities due to trachoma (CO). Active trachoma was defined as the presence of TF or TI in either eye. If both eyes had trachoma, the classification was based on the eye with the more severe disease.

Risk factors for trachoma were collected at the ward, household, maternal, and individual child levels. Types of water sources available in the ward and the access to water at the household level were ascertained. Markers of crowding included number of houses per ward, number of household members, and number of people per room. Because of the systematic sampling within selected wards, children participating in the survey came from different households. Hence, we were unable to look at presence of trachoma in other siblings as a risk factor for household transmission. Markers of socioeconomic status included literacy and occupation of the head of the household, number of servants, house construction, presence and type of latrine, and ownership of household goods, animals, and land. Maternal characteristics included age, literacy, and number of children who had died. Morbidity of children in the past week was also known based on a history obtained from the mother.

Pairwise odds ratios were used to estimate the clustering of trachoma within wards and to estimate the design effect generated by cluster sampling. ${ }^{112}$ Confidence intervals for the prevalence of trachoma were adjusted to account for the clustering of disease within wards. The association between trachoma and each risk factor was examined separately. Factors that were associated with $p$ values of 0.1 or less were included in a logistic regres-
Table 2 Distribution of number of children sampled and active trachoma prevalence by wards

\begin{tabular}{lrr} 
& $n$ & $\%$ \\
\hline No of children sampled per ward: & & \\
$<10$ & 6 & 15.0 \\
$10-19$ & 18 & 45.0 \\
$20-29$ & 6 & 15.0 \\
$30-39$ & 6 & 15.0 \\
$40-49$ & 2 & 5.0 \\
$50-59$ & 2 & 5.0 \\
Total & 40 & 100.0 \\
Ward prevalence (\%) & & \\
$0-9$ & 8 & 20.0 \\
$10-19$ & 11 & 27.5 \\
$20-29$ & 5 & 12.5 \\
$30-39$ & 10 & 25.0 \\
$40-49$ & 4 & 10.0 \\
$50-59$ & 2 & 5.0 \\
Total & 40 & 100.0 \\
\hline
\end{tabular}

sion model to assess the strength of the association between trachoma and multiple risk factors.

Ethical approval for this study was obtained from the Joint Committee on Clinical Investigations of the Johns Hopkins University, and by the Nepal Health Research Council. Verbal informed consent was obtained from parents of children selected to participate. Children found to have trachoma were treated with tetracycline ointment in both eyes twice daily for 5 consecutive days.

\section{Results}

A total of 891 children between the ages of 24 and 76 months from 890 households were systematically selected for the survey from the census lists of the 40 ocular survey wards. Of these, $836(93.7 \%)$ were examined for signs of trachoma. The lowest response rate was among 2 year old girls at $86.5 \%$. There were six children where only one eye was examined. The fellow eyes of each of these children were normal and the child was classified as normal for purposes of estimating prevalence. The prevalence of all active disease was $23.6 \%$ (95\% confidence interval (CI): 19.0, 28.2). The prevalence of follicular trachoma and intense inflammatory trachoma was $21.9 \%$ and $1.7 \%$, respectively. No cases of cicatricial trachoma were seen in this population. The highest prevalence of both follicular and intense inflammatory trachoma was found in 3 year old children (Table 1). The overall prevalence was $23.0 \%$ for males and $24.2 \%$ for females. All cases of intense inflammatory disease were bilateral, whereas $16 \%$ of those with follicular disease were observed in one eye only.

The distribution of the number of children sampled in each ward is given in Table 2. The numbers ranged from 3 to 53 since those sampled were a $20 \%$ systematic sample of children from each ward who were in the eligible age range. Because of the systematic sampling of every fifth child from the census lists, all children except one were from different households. The prevalence of trachoma in the different wards ranged from zero to $50 \%$, with $20 \%$ of the wards having prevalence rates below $10 \%$ and $15 \%$ of the wards having prevalence rates of $40 \%$ and higher (Table 2). There was a large variation in prevalence rates 
Table 3 Risk factors for active trachoma in Sarlahi district, Nepal

\begin{tabular}{|c|c|c|c|c|c|}
\hline \multirow[b]{2}{*}{ Risk factors } & \multirow[b]{2}{*}{ No } & \multirow[b]{2}{*}{ Prevalence (\%) } & \multicolumn{2}{|c|}{ Odds ratios } & \multirow[b]{2}{*}{$95 \% C I$} \\
\hline & & & Crude & Adjusted ${ }^{\star}$ & \\
\hline \multicolumn{6}{|l|}{ Servants: } \\
\hline None & 747 & 24.9 & & & \\
\hline Any & 83 & 13.3 & 0.46 & 0.69 & $0.33,1.44$ \\
\hline \multicolumn{6}{|l|}{ People/room: } \\
\hline$<5$ & 478 & 20.5 & & & \\
\hline$\geq 5$ & 352 & 28.1 & 1.52 & 1.46 & $1.03,1.75$ \\
\hline \multicolumn{6}{|c|}{ Irrigated land (biggars $\dagger$ ): } \\
\hline$<20$ & 510 & 26.3 & & & \\
\hline $20-99$ & 266 & 22.6 & 0.84 & 1.01 & $0.68,1.50$ \\
\hline$\geq 100$ & 54 & 5.6 & 0.21 & 0.39 & $0.11,1.40$ \\
\hline \multicolumn{6}{|l|}{ Bicycles owned: } \\
\hline None & 685 & 25.1 & & & \\
\hline Any & 145 & 17.2 & 0.62 & 0.85 & $0.51,1.42$ \\
\hline \multicolumn{6}{|l|}{ Type of house: } \\
\hline Thatch only & 273 & 25.3 & & & \\
\hline Bamboo/thatch/tile & 372 & 20.2 & 0.75 & 0.90 & $0.59,1.35$ \\
\hline Wood/thatch/tile & 148 & 34.5 & 1.55 & 1.54 & $0.92,2.56$ \\
\hline Cement/tile & 37 & 5.4 & 0.17 & 0.27 & $0.06,1.17$ \\
\hline \multicolumn{6}{|c|}{ Primary household water source: } \\
\hline Tube well & 412 & 21.6 & & & \\
\hline Ring well & 350 & 26.9 & 1.33 & 0.87 & $0.56,1.34$ \\
\hline Unprotected & 68 & 20.6 & 0.94 & 0.52 & $0.23,1.17$ \\
\hline \multicolumn{6}{|c|}{ Houses/water source in ward: } \\
\hline$<10$ & 389 & 20.8 & & & \\
\hline $10-29$ & 253 & 25.3 & 1.29 & 1.07 & $0.68,1.67$ \\
\hline$\geq 30$ & 194 & 27.8 & 1.47 & 0.90 & $0.46,1.78$ \\
\hline \multicolumn{6}{|l|}{ Tube wells in ward: } \\
\hline None & 191 & 34.0 & & & \\
\hline Any & 645 & 20.5 & 0.50 & 0.53 & $0.30,0.93$ \\
\hline \multicolumn{6}{|l|}{ Pharmacies in ward: } \\
\hline None & 710 & 24.6 & & & \\
\hline Any & 126 & 17.5 & 0.65 & 0.86 & $0.49,1.51$ \\
\hline
\end{tabular}

Six households could not be interviewed and are missing household specific data.

^Adjusted for age of the child in years (separate odds ratios for each year) and all other factors listed in this table.

$\dagger 1$ biggar $=1.67$ acres. wells (Table 3). Ring wells were the primary water source for $42.2 \%$ of households. Unprotected water sources such as ponds, streams, and rivers were the primary source for only $8.2 \%$ of households. Eighty nine per cent of households were within 30 minutes' walk of their primary water source, and $33 \%$ were within 5 minutes' walk. There was no association between the distance to the primary water source and the risk of trachoma to children in that household.

In a bivariate analysis, household characteristics that were significantly associated with trachoma risk were the presence of servants, number of household members per room, ownership of irrigated land, bicycle ownership, and type of housing (Table 3). Several differences that were not statistically significant were observed between households with and without trachoma. Trachoma was less prevalent among households where the head of household's occupation was a private business or service $(19.1 \%)$ compared with farmers or labourers $(28.5 \%)$. Trachoma prevalence was lower in households with a pit or water sealed latrine $(19.6 \%)$ compared with households without any latrine (24.0\%). Brahmins and non-Hindus had lower rates of trachoma than other castes (19.8\% and $14.0 \%$, respectively). Households with trachoma owned fewer carts, radios, watches, and animals. Literacy of the head of the household was not associated with trachoma (24.1\% among those not literate versus $23.3 \%$ among those who were). This was the case in spite of the fact that head of household literacy was associated with ownership of household goods, employment of servants, and caste.

Maternal literacy was associated with a lower risk of trachoma (17.6\% versus $23.7 \%$ ) but this difference was not statistically significant because of the low rates of literacy in this population $(8.2 \%)$. Maternal age and whether the mother had previous children who had died was not associated with trachoma risk. The prevalence of trachoma was higher among children who had been sick in the past week ( $26.9 \%$ versus $22.6 \%$ ), but this difference was not statistically significant.

Risk factors that were significantly associated with trachoma risk in bivariate analyses were entered into a multivariate logistic regression model (Table 3). Factors that remained significant at the 0.05 level in this model were number of people per room and the presence of one or more tube well in the ward. The odds of trachoma were 1.46 (95\% CI: $1.03,1.75)$ times greater for children from households with five or more people per room than households with fewer people per room. The odds of trachoma were 0.53 (95\% CI: $0.30,0.93$ ) for children living in wards with at least one tube well compared with those in wards without any tube wells. The presence of a tube well in the ward was more important as a protection against trachoma than the use of the tube well as the primary water source for individual households.

An analysis was also done separately for the 19 low prevalence wards $(<20 \%$ of children

Tube wells were the main water source for $49.6 \%$ of all households since these were more numerous within the wards that did have tube 
with trachoma) and the 16 high prevalence wards ( $>30 \%$ of children with trachoma). Among low prevalence wards, the only significant risk factor was the number of people per room (odds ratio: 1.85 for five or more people per room, $95 \% \mathrm{CI}: 0.95,3.58)$. Among high prevalence wards, the employment of one or more servants was the only factors significantly associated with a lower risk of trachoma (odds ratio: $0.39,95 \%$ confidence interval: 0.14 , $0.96)$. The presence of tube wells in the ward was not associated with trachoma in the high or low prevalence wards because this was a characteristic of the ward. The presence of tube wells explained some of the variation between high and low prevalence wards, but not the variation within low prevalence or high prevalence strata.

\section{Discussion}

Follicular trachoma is prevalent in this population although very few children had intense active inflammatory disease. Cicatricial trachoma was not seen in this population but this is probably due to the young age of the population examined. The prevalence of intense inflammatory trachoma has been found to be much higher in Africa, ${ }^{13-18}$ South Asia, ${ }^{19-21}$ and among Australian aboriginal populations. ${ }^{22} 23$ Our rates of intense inflammation were comparable with those found in Sao Paulo, Brazil, although their rates of follicular disease were lower. ${ }^{24}$ Because of the low rates of intense inflammatory trachoma, the Sarlahi population is at low risk for scarring and corneal opacification in adulthood. Adults were not examined so we are unable to say anything about the prevalence of trichiasis/entropion or the need for surgery in the adult population since this would represent the sequelae of childhood exposures 40-60 years ago.

The Nepal Blindness Survey found that the prevalence of trachoma was highest in the far west $(28.5 \%$ for males and $31.9 \%$ for females). ${ }^{2}$ The prevalence of active trachoma among preschool children in our study area (east central terai) was comparable with that for all age groups in Bheri and Seti zones (far west) in 1981, and much higher than that reported from the eastern terai in 1981. The Nepal Blindness Survey did not report trachoma prevalence by age and geographical zone. Hence, an age specific comparison is not possible. Gilbert and Marx studied sociomedical factors associated with trachoma risk within the Nepal Blindness Survey. ${ }^{2526}$ Our study found a similar pattern of trachoma risk in different castes to that observed in the Nepal Blindness Survey. The prevalence of trachoma was slightly lower among Brahmins and non-Hindus (mostly Muslims and a few Buddhists), and highest among the Chhetris. In the blindness survey, watch ownership, as a reflection of family wealth, was associated with lower rates of trachoma. We found households that owned bicycles, watches, and carts had lower rates of trachoma, although these were strongly associated with other more closely associated factors such as type of housing, crowding, and type of water source. Studies in other parts of South Asia found associations between caste and trachoma risk, ${ }^{19}$ personal hygiene and education level of parents, ${ }^{20}$ and general socioeconomic status. ${ }^{21}$

Lower socioeconomic status has been associated with higher risk of trachoma in many dif-

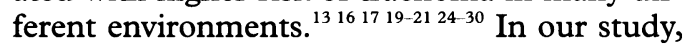
better housing, non-agricultural cash employment, presence of a latrine, and ownership of land, animals, and household goods were each associated with slightly lower rates of trachoma. The type of water source was more important as a risk factor for trachoma than access to water as measured by time taken to walk to the water source. The presence of one or more tube wells in a ward and the household use of tube wells were both associated with lower rates of trachoma than the presence and use of ring wells. Seven of the nine wards without tube wells did have access to ring wells but still had higher rates of trachoma than those wards with tube wells. This may reflect poorer access to water from ring wells compared with tube wells. More effort is required to pull water from a ring well than to access a tube well, and this might reduce the volume used by the household. Alternately, the absence of tube wells in the ward or their use by families might be a marker for other socioeconomic or hygiene factors associated with trachoma risk. Since the presence of tube wells in the ward was more strongly associated with lower trachoma risk than the use of tube wells as the primary water source for a household, the latter is the more likely explanation.

Water access and consequent quantity of water used is important because it is associated with facial cleanliness which has been shown to be associated with trachoma in observational studies. ${ }^{132931-33}$ A community intervention to increase face washing was able to demonstrate a reduction in trachoma prevalence. ${ }^{34} \mathrm{~A}$ study in the Gambia found an association between the amount of water used to wash children and trachoma risk. ${ }^{35}$ In Brazil, almost all households had access to piped water, but water piped into the house, rather than accessible nearby, was protective against trachoma. ${ }^{24}$ The type of water source was also found to be important in Taiwan where lower rates of trachoma were found in households with internal piped water compared with hand pumps and draw wells. ${ }^{27}$ In general, access was quite good in this population compared with many parts of Africa. Only $11 \%$ of households had to walk more than 30 minutes to their primary water source, compared with $80 \%$ of households in Kongwa, Tanzania. ${ }^{31}{ }^{36}$ However, a strong association was seen between distance to water and trachoma prevalence in Malawi, where only $13 \%$ of children came from households where the primary water source was more than 30 minutes' walk from the house. ${ }^{13}$ Distance to a water source has generally been found to be more strongly associated with trachoma risk than quantity or quality of water. ${ }^{37}$ In Nepal, access, as measured by the number of houses per water source within a ward, was marginally associated with higher rates of 
trachoma but only for wards with more than 30 houses per water source.

Extensive crowding and poor hygiene result in repeated infections within households and within neighbourhoods. Repeat infections lead to scarring of the conjunctiva among school age children and young adults that results in trichiasis/entropion and blindness among older adults. Crowding, as measured by the number of household members per room, was found to be a risk factor for trachoma in our study in Nepal. Others have also shown this association. ${ }^{1524}$ The presence of siblings with trachoma was not examined in this study because of the way children were sampled, but this has been shown to be strongly associated with trachoma risk in several studies. ${ }^{13172838}$ Our measure of crowding was probably a surrogate for the number of preschool age children who act as the main reservoir of active trachoma.

Follicular but not intense inflammatory trachoma was common among preschool children in this area of Nepal. Given the prevalence and severity seen in this population, the risk of blindness from trachoma should be relatively low if environmental conditions remain the same over time. Nevertheless, it is important to note that trichiasis/entropion is still seen in clinic settings among older patients in this area. Hence, modest rates of active disease among children does not necessarily translate into reduced need for trichiasis/ entropion surgery in the adult population. Although active trachoma is not endemic in this area, it is important not to ignore the problem of active trachoma because a pool of infection clearly exists that can increase the severity and intensity of the disease if the environmental conditions change for the worse, particularly if crowding increases or if access to water is reduced from current levels.

This work was carried out under cooperative agreement no DAN 0045-A-5094 between the Office of Nutrition, US Agency for International Development (USAID), Washington, DC, the Center for Human Nutrition (CHN), and the Dana Center for Preventive Ophthalmology (DCPO) at Johns Hopkins University. It was a joint undertaking between CHN/DCPO and the National Society for the Prevention of Blindness, Kathmandu, Nepal.

This study was funded by USAID, with financial and technical assistance from Task Force Sight and Life (Roche, Basel) the United Nations Children's Fund (UNICEF), Nepal, and

the United Nations Childre

The Sarlahi Study Group comprises (in addition to the authors): Dr A Sommer, Dr R P Pokhrel, D N Mandal, T R Shakya, N Acharya, Dr J M Tielsch, Dr J Humphrey, L Clement, Dr J Gmunder, Dr R A Adhikari, Dr F R Davidson, Dr D Calder, and D Piet.

1 Adamson I, Taylor HR. Major causes of world blindness: their treatment and prevention. Curr Opin Ophthalmol their treatment

2 Thylefors B, Negrel AD, Pararajasegaram R. Epidemiologic aspects of global blindness prevention. Curr Opin Ophthalmol 1992;3:824-34.

3 Brilliant GE, ed. The epidemiology of blindness in Nepal. Chelsea, Michigan: Seva Foundation, 1988.

4 Brilliant LB, Pokhrel RP, Grasset NC, Kolstad A, Lepkowski J, Brilliant $\mathrm{G}$, et al. Epidemiology of blindness in Nepal. Bull World Health Organ 1985;63:375-86.

5 West KP Jr, Pokhrel RP, Katz J, LeClerq SC, Khatry SK, Shrestha SR, et al. Efficacy of vitamin A in reducing preschool child mortality in Nepal. Lancet 1991;338:67-71.

6 Pradhan EK, Katz J, LeClerq SC, West KP Jr. Data management for large community trials in Nepal. Control management for large com

7 West KP Jr, Katz J, Shrestha SR, LeClerq SC, Khatry SK, West KP Jr, Katz J, Shrestha SR, LeClerq SC, Khatry SK,
Pradhan EK, et al. Mortality of infants $<6$ months of age Pradhan EK, et al. Mortality of infants $<6$ months of age
supplemented with vitamin A: a randomized, doublemasked trial in Nepal. Am $\mathcal{F}$ Clin Nutr 1995;62:143-8.
8 Katz J, West KP, Khatry SK, Thapa MD, LeClerq SC, Pradhan EK, et al. The impact of vitamin A supplementation on prevalence and incidence of xerophthalmia in Nepal. Invest Ophthalmol Vis Sci 1995;36:2577-83.

9 Thylefors B, Dawson CR, Jones BR, West SK, Taylor HR. A simple system for the assessment of trachoma and its complications. Bull World Health Organ 1987;65:477-83.

10 Taylor HR, West SK, Katala S, Foster A. Trachoma: evaluation of a new grading scheme in the United Republic of Tanzania. Bull World Health Organ 1987;65:485-8.

11 Carey VJ, Zeger SL, Diggle PJ. Modelling multivariate binary data with alternating logistic regression. Biometrika 1993;80:517-26.

12 Katz J, Zeger SL. Estimation of design effects in cluster surveys. Ann Epidemiol 1994;4:295-301.

13 Tielsch JM, West KP Jr, Katz J, Keyvan-Larijani E, Tizazu T, Schwab L, et al. The epidemiology of trachoma in southern Malawi. Am f Trop Med Hyg 1988;38:393-9.

14 de Sole JG. Impact of cattle on the prevalence and severity of trachoma. Br F Ophthalmol 1987;71:873-6.

15 Sahlu $T$, Larson $C$. The prevalence and environmental risk factors for moderate and severe trachoma in southern Ethiopia. F Trop Med Hyg 1992;95:36-41.

16 Courtright P, Sheppard J, Schachter J, Said ME, Dawson CR. Trachoma and blindness in the Nile Delta: current patterns and projections for the future in the rural Egyptian population. Br f Ophthalmol 1989;73:536-40.

17 West SK, Rapoza P, Munoz B, Katala S, Taylor HR. Epidemiology of ocular chlamydial infection in a trachomahyperendemic area. F Infect Dis 1991;163:752-6.

18 Schwab L, Whitfield R, Ross-Degnan D, Steinkuller P, Swartwood J. The epidemiology of trachoma in rural Kenya. Variation in prevalence with lifestyle and environment. Ophthalmology 1995;102:475-82.

19 Sharma JL, Lal S, Chauhan BS, Singh M, Singh I. Epidemiological survey of prevalence of trachoma among school children in Haryana State. Ind $\mathcal{f}$ Pub Health 1975;19:63-8.

20 Srivastava BC, Chandra R, Srivastava VK, Saxena SC, Nandan D, Gupta RP. Prevalence of trachoma in school children of a rural community. Indian Paediatr 1981;18: 233-6.

21 Werner GT, Sareen DK. Trachoma in Punjab, a study of the prevalence and of mass treatment. Trop Geogr Med $1977 ; 29 \cdot 35-140$.

22 Stocks NP, Newland H, Hiller J. The epidemiology of blindness and trachoma in the Anangu Pitjantjatjara of South Australia. Med ₹ Aust 1994;160:751-6.

23 Taylor HR. Prevalence and causes of blindness in Australian aborigines. Med f Aust 1980;26:71-6.

24 Luna EJA, Medina NH, Oliveira MB, de Barros OM, Vranjac A, Melles HHB, et al. Epidemiology of trachoma in Bebedouro State of Sao Paulo, Brazil: prevalence and risk factors. Int $\mathcal{F}$ Epidemiol 1991;20:169-77.

25 Gilbert SS. Trachoma in Nepal: an investigation into sociocultural and individual factors. PhD dissertation. Ann Arbor, Michigan, 1983

26 Marx R. Sociomedical aspects of trachoma. Acta Opthalmol 1988;66(suppl):16-36.

27 Assaad FA, Maxwell-Lyons F, Sundaresan T. Use of local variation in trachoma endemicity in depicting interplay between socioeconomic conditions and disease. Bull World Health Organ 1969;41:181-94.

28 Courtright P, Sheppard J, Lane S, Sadek A, Schachter J, Dawson CR. Latrine ownership as a protective factor in inflammatory trachoma in Egypt. Br f Ophthalmol 1991;75: 322-5.

29 Taylor HR, West SK, Mmbaga BBO, Katala SJ, Turner V, Lynch $\mathrm{M}$, et al. Hygiene factors and increased risk of trachoma in central Tanzania. Arch Ophthalmol 1989;107: 1821-5.

30 Marx R. Social factors and trachoma: a review of the literature. Soc Sci Med 1989;29:23-34.

31 West SK, Lynch M, Turner V, Munoz B, Rapoza P, Mmbaga $\mathrm{BBO}$, et al. Water availability and trachoma. Bull World Health Organ 1989;67:71-5.

32 Taylor HR, Millan-Velasco F, Sommer A. The ecology of trachoma: an epidemiological study of trachoma in southern Mexico. Bull World Health Organ 1985;63:559-67.

33 West SK, Congdon N, Katala S, Mele L. Facial cleanliness and risk of trachoma. Arch Ophthalmol 1991;109:855-7.

34 West SK, Munoz B, Lynch M, Kayongoya A, Chilangwa Z, Mmbaga BB, et al. Impact of face-washing on trachoma in Kongwa, Tanzania. Lancet 1995;345:155-8.

35 Bailey R, Downes B, Downes R, Mabey D. Trachoma and water use; a case control study in a Gambian village. Trans Royal Soc Trop Med Hyg 1991;85:824-8.

36 McCauley AP, Lynch M, Pounds MB, West S. Changing water-use patterns in a waterpoor area: lessons for a trachoma intervention project. Soc Sci Med 1990;31:12338.

37 Prost A, Negrel AD. Water, trachoma and conjunctivitis. Bull World Health Organ 1989;67:9-18.

38 West SK, Munoz B, Lynch M, Kayongoya A, Mmbaga BBO, Taylor HR. Risk factors for constant, severe trachoma among preschool children in Kongwa, Tanzania. Am $\mathcal{F}$ Epidemiol 1996;143:73-8. 